\title{
PERSPECTIVAS INTERDISCIPLINAR E RIZOMÁTICA NA FORMAÇÃO DOS PROFISSIONAIS DA SAÚDE
}

\author{
INTERDISCIPLINARY AND RHIZOMATIC PERSPECTIVES IN THE FORMATION OF THE HEALTH \\ PROFESSIONALS
}

Maria Helena Salgado Bagnato 1

Maria Inês Monteiro ${ }^{2}$

Resumo Este artigo tem como objetivo problematizar aspectos das perspectivas interdisciplinar e rizomática na formação de profissionais da área da saúde. Ambas as atitudes requerem olhares plurais e outras posturas dos educadores nas relações que estabelecem com os sujeitos e com os conhecimentos, visando a superar maneiras fragmentadas dos processos de trabalho e de produção de ciência, recuperando o caráter dialético da realidade social. Os desafios postos por estas perspectivas convidam todos os educadores envolvidos eticamente neste processo a refletirem sobre a inclusão de temas e dimensões que perpassam transversalmente o processo de formação profissional e a produção de conhecimentos, movimentando territórios, compreensões e subjetividades, o que pode possibilitar interpretações inovadoras e polissêmicas, bastante desejáveis para se lidar com a complexidade da realidade, inclusive na área da saúde.

Palavras-chave ensino em saúde; interdisciplinaridade; rizoma; educação.

\begin{abstract}
This purpose of this article is to problemize aspects of the interdisciplinary and rhizomatic in the formation of professionals from the health area. Both attitudes require plural looks and other postures from the educators in the relationships that they establish with the subjects and with the knowledge, seeking to overcome fragmented manners of the labor processors and the production of science, recovering the dialectic character of the social reality. The challenges posed by these perspectives invite all the educators ethically involved in this to reflect on the inclusion of themes and dimensions that pass transversally by professional formation process and the production of knowledge, moving territories, comprehensions and subjectivities, which can enable innovative and polysemic interpretations, very desirable to deal with the complexity of reality, also in the health area.
\end{abstract}

Key words teaching in health; interdisciplinarity; rhizoma; education. 


\section{Situando a discussão: fragmentos de um cenário complexo}

“(...) não se pode observar uma onda sem levar em conta os aspectos complexos que concorrem para formá-la e aqueles também complexos a que essa dá ensejo".

(Ítalo Calvino, Palomar)

A educação e o ensino na área da saúde têm merecido, nas duas últimas décadas, atenção especial nos debates e nas produções dos educadores envolvidos com a formação dos profissionais, visando a superar um modelo predominantemente técnico, linear, compartimentalizado, ainda freqüente nos currículos de alguns cursos e que já não tem atendido aos anseios e necessidades dos profissionais e da população usuária dos serviços de saúde.

O paradigma linear pauta-se, principalmente, pela orientação racionaltécnica, em que se fazem presentes os pressupostos tayloristas que valorizam formas de organização do trabalho parcelado e ampliação da capacidade técnica. Esta perspectiva ainda predomina em muitos cursos universitários, e nela a formação profissional, inclusive na saúde, tende a se articular às demandas imediatas do mercado, e não necessariamente às necessidades decorrentes do contexto social.

Este paradigma pode encontrar espaço nas práticas pedagógicas dos professores universitários através da proposta do modelo de competência, por exemplo, presente nas diretrizes curriculares dos cursos na área da saúde, quando entendido e implementado de maneira restritiva ao processo técnico. A absolutização dos conhecimentos, as certezas prescritivas, as explicações unidimensionais e unirreferenciais colaboram para uma formação pouco crítica e fomentam a ideologia do controle e da simplificação dos fenômenos.

Também a fragmentação dos conhecimentos em disciplinas, o distanciamento entre teoria e prática, pensar e fazer, entre conhecimento 'científico' e 'popular' provocam rupturas que dificultam uma visão mais abrangente na formação dos profissionais, que se deparam com novas exigências da contemporaneidade, em cenários complexos, sempre em movimento.

A configuração de espaços e tempos contínuos para análises e problematizações do processo de formação profissional permite explicitar e problematizar quais dimensões dos conhecimentos predominam neste processo, que contornos as práticas, a organização e a gestão dos processos de trabalho em saúde assumem, quais são as relações de poder e saber que se estabelecem nos serviços de saúde, as políticas de saúde que vigoram, a produção de conhecimentos que está sendo financiada, entre outros aspectos.

Neste contexto, os cursos da área da saúde e os processos de formação vêm sendo repensados nas dimensões do ensino, pesquisa e extensão, objetivando novas formas de ver o conhecimento, a formação profissional, o 
ensino universitário, as parcerias com a sociedade. Algumas destas mudanças pretendem ser mais profundas, enquanto outras acabam sendo mais periféricas ou pontuais.

Com o propósito de avaliar a 'positividade' de mudanças propostas sobre o assunto no Brasil (Castanho, 2002; Chirelli e Missiva, 2003; Bagnato e Rodrigues, 2004; Batista, 2005; Fagundes e Burnham, 2005; Ruiz-Moreno et al., 2005), encontramos algumas iniciativas que envolvem:

- discussões e (re)elaborações dos projetos pedagógicos dos cursos, destacando o estabelecimento de outras bases para as relações sujeitos educativos e educador, sujeitos e conhecimentos, campo do conhecimento específico e contexto socioeconômico e político, formas diferenciadas de entendimentos e usos de processos de avaliação formativa;

- outras formas de organização curricular, como, por exemplo, por áreas de conhecimento, projetos, módulos e competências;

- inserção de metodologias de problematização e da aprendizagem baseada em problemas;

- projetos de ensino, pesquisa e extensão que contemplam diagnósticos das necessidades da comunidade e propostas de intervenção;

- parcerias com os profissionais dos serviços para planejamento dos projetos dos cursos.

A assunção de perspectivas teórico-epistemológicas denominadas interdisciplinar e rizomática também tem se inscrito nestas discussões, com pressupostos que buscam contribuir com outras leituras polissêmicas dos conhecimentos e superar concepções e práticas fragmentárias, objetivando movimentar paradigmas da formação e das práticas dos profissionais da saúde.

Estudiosos desta temática, como Morin (1999, 2000), Gallo (2000), Pombo (2005), apontam para algumas possibilidades que estas perspectivas trazem de articulações dos conhecimentos, com uma nova reorganização e compreensão epistemológica de diferentes campos do saber, ensejando-se assim outras concepções de educação, de formação, de organização e produção de conhecimentos e de trabalho que contemplem as mudanças e as necessidades da área da saúde.

Temos clareza de que a complexidade desta discussão não nos permite visões e saídas simplistas, pois a saúde, enquanto dimensão da área social, está imersa e condicionada por um contexto político, econômico, social e cultural mais geral. No entanto, assumir processos de formação numa perspectiva histórica, plural e aprofundar questionamentos que problematizem os recortes culturais - o porquê da escolha de um corpo de conhecimento que fará parte da formação e não de outros, a importância da incorporação de outras dimensões (multidimensionalidade e multirreferencialidade) ao processo educativo - poderá incomodar muitos dos que participam deste 
processo, e esse incômodo pode vir a se constituir em desafios, reflexões e início de mudanças concretas nos microcontextos.

Em diferentes áreas do conhecimento, inclusive na saúde, há um avanço nos discursos e nas práticas, sobre a compreensão e a importância do trabalho interdisciplinar na formação profissional, sendo este princípio muitas vezes explicitado como um dos eixos condutores do trabalho educativo, nos projetos pedagógicos dos cursos e nas diretrizes curriculares.

Diante da diversidade dos elementos supracitados, presentes nas discussões do ensino na área da saúde, optamos por abordar, neste texto, aspectos das perspectivas interdisciplinar e rizomática, insistindo na possibilidade de serem contempladas neste nível de ensino, potencializando algumas cisões com um modelo cartesiano e binário de ciência e de realidade.

Fomentar discussões sobre esses aportes na formação para a área da saúde pode contribuir para movimentar os olhares dos profissionais para as diferentes realidades político-socioculturais nas quais irão atuar e que demandarão saberes e competências, entendidos para além da dimensão técnica, incluindo as dimensões ética, política, humana e estética.

\section{Retomando e ampliando algumas idéias}

"A fixidez é sempre momentânea". (Otávio Paz, O monogramático)

Alguns autores, como Santos Filho (1992), Morin (1999, 2000), Gallo (2000), Pombo (2005), têm contribuído com instigantes reflexões a respeito das perspectivas interdisciplinar e rizomática no ensino, mostrando que a organização curricular disciplinar, compartimentalizada, estanque, reflete e traz as marcas da divisão histórica das atividades humanas no mundo do trabalho, imposta pelo modelo econômico à maioria da população. Uma conseqüência disso pode ser a formação de sujeitos alienados, pois a alguns é dado o direito de pensar, refletir, propor, produzir; e a muitos resta o fazer, o cumprir tarefas, atividades estas dissociadas do processo de gestão, de criação (Freitas, 1989; Frigotto, 1995). Como em outras áreas, essas divisões também aparecem nas atividades de ensino, assistência e pesquisa na área da saúde.

Sabemos que o processo de formação profissional, entendido como um conjunto de experiências, práticas, vivências e conhecimentos aprendidos e compartilhados em um campo específico e em outros espaços, está indissociavelmente nos constituindo também enquanto pessoas, delineando identidades e subjetividades, mais submissas ou resistentes ao modelo e às conseqüências da atual organização capitalista. 
Assim, ao analisarmos as questões relativas à formação dos profissionais, contempladas nas formas de organização e compreensão do ensino na área da saúde, temos de lançar também um olhar investigativo e crítico ao modelo capitalista de sociedade, à divisão social do trabalho, às políticas sociais, pois pensar outras formas de atenção à saúde para a população implica, entre outras atitudes, rever as relações de trabalho no setor, as características dos profissionais que estão sendo formados, remetendo-nos aos pressupostos que têm respaldado suas formações e práticas.

Na medida em que predomina uma formação que decompõe um campo de conhecimento (na perspectiva disciplinar) e que dificilmente volta a (re)compô-lo em sua complexidade, articulando-o com outras dimensões, os profissionais poderão realizar práticas fragmentadas, olhando o sujeito ('objeto' de suas práticas) em partes, numa ótica especializada que tende a se guiar por uma lógica que dificilmente dá espaço para a criação, ou que estabelece poucos canais de comunicação com outros saberes, ficando difícil a recontextualização e as interconexões desses saberes.

Ao atentarmos para as conseqüências da produção de conhecimentos e de práticas fragmentadas no campo da saúde, começamos a questionar e problematizar as dificuldades e resistências ao trabalho em grupo, em equipe; as práticas e experiências que ainda acontecem, muitas vezes, mais de maneira individualizada, solitária, do que compartilhada, socializada, solidária; a maneira como se qualificam alguns trabalhos, trabalhadores e conhecimentos e se desqualificam outros; as exigências quantitativas de produtividade que não propiciam um tempo de experiência para projetos de pesquisa coletivos, entre outros.

Em um processo de reflexão-ação-reflexão destes cenários, é possível avançar para outras maneiras de pensar e fazer educação e práticas de saúde, assumindo compromisso com propostas que favoreçam as multiplicidades, recuperando as conexões, os fluxos, movimentando fronteiras, instaurando outras lógicas.

Entendemos que a perspectiva interdisciplinar traz importantes contribuições para o campo do conhecimento e da educação em saúde, buscando superar a fragmentação dos conhecimentos e a excessiva especialização. No entanto, gostaríamos de trazer algumas idéias que Gallo (2000) acrescenta a estas discussões, apoiando-se no conceito de rizoma (Deleuze e Guattari, 1995, 1997), ainda pouco explorado no campo da educação e saúde.

Esta perspectiva parte de uma visão de realidade(s) complexa e plural - constituída por múltiplas culturas, realidades sociais, comunicacionais e linguagens - que produz questões e desafios, que não podem ser abarcados por uma única disciplina ou área. "Para pensar problemas híbridos, necessitamos de saberes híbridos para além dos saberes disci- 
plinares" (Gallo, 2000, p. 28), em que o pensamento e o conhecimento podem se manifestar menos hierarquizados e mais caóticos, rompendo com a linearidade.

No que concerne à interdisciplinaridade, esta tem sido uma temática que desafia os estudiosos, tanto pela possibilidade de diferentes modos de compreensão de sua terminologia, significados (diferentes visões filosóficas e epistemológicas do que constitui uma disciplina), da função sociopolítica que desempenha no modelo hegemônico de ciência, quanto pela complexidade de sua inserção como pressuposto teórico-metodológico no cotidiano das práticas pedagógicas, configurando-se assim como um campo em construção (Santos Filho, 1992).

Para Freitas (1989), a perspectiva interdisciplinar pode ser entendida como integração, como interpenetração de conteúdos e métodos de disciplinas que se propõem a trabalhar, construir conhecimento, de maneira conjunta sobre um determinado objeto de estudo, situando este conhecimento historicamente no campo da ciência, entendendo, no entanto, que a interdisciplinaridade não pode por si devolver a totalidade do conhecimento.

Assim, esta perspectiva busca não apenas a mera agregação de diferentes disciplinas ou conhecimentos, mas também a articulação de conhecimentos diversos que se somam e interagem, possibilitando a construção de novos conhecimentos, diferentes dos iniciais. Pode promover mudanças nas relações entre sujeitos, e entre sujeitos e conhecimentos, considerando a multidimensionalidade e a multirreferencialidade, perseguindo uma leitura polissêmica dos conhecimentos e do mundo. Aposta na interlocução, na relação dialógica entre sujeitos com competências em diferentes campos do saber, para superar as maneiras fragmentadas dos processos de trabalho, de produção de ciência, recuperando o caráter dialético da realidade social, que é "ao mesmo tempo una e diversa na natureza intersubjetiva de sua apreensão" (Frigotto, 1995, p. 27), atentando para as múltiplas determinações que constituem o conhecimento.

Por sua vez, Gallo (2000, p. 30), apoiando-se em Deleuze e Guattari, expressa a metáfora do rizoma como "inúmeras linhas fibrosas (...), que se entrelaçam e se engalfinham formando um conjunto complexo, no qual os elementos remetem necessariamente uns aos outros e mesmo para fora do próprio conjunto".

Afirma ainda que "no rizoma são múltiplas as linhas de fuga e, portanto múltiplas possibilidades de conexões, aproximações, cortes, percepções etc." (Gallo, 2000, p. 32).

Assim, podem-se criar fluxos de compreensão, concepções e produções que tomam qualquer direção, sem nenhuma hierarquia definida antecipadamente. “O rizoma conecta um ponto qualquer com outro ponto 
qualquer e cada um de seus traços não remete necessariamente a traços da mesma natureza; ele põe em jogo regimes de signos muito diferentes, inclusive estados de não signos" (Deleuze e Guattari, 1995, p. 32).

O conceito de rizoma foi proposto como ponto de partida para se pensar as multiplicidades por elas mesmas, visto que o fundamento do rizoma é a própria multiplicidade. "A multiplicidade não deve designar uma combinação de múltiplo e uno, mas, pelo contrário, uma organização própria do múltiplo como tal, que de modo nenhum tem necessidade da unidade para formar um sistema" (Deleuze, 1988, p. 303).

É oportuno enumerar algumas características iniciais do rizoma, para posteriormente refletirmos sobre esse conceito em uma perspectiva mais ampla.

A compreensão rizomática é composta por seis princípios, segundo Gallo:

“a) conexão - qualquer ponto de um rizoma pode ser/estar conectado a qualquer outro (...); b) heterogeneidade - dado que qualquer conexão é possível, o rizoma rege-se pela heterogeneidade (...); c) multiplicidade - o rizoma é sempre multiplicidade que não pode ser reduzida à unidade (...) o rizoma não é sujeito nem objeto, mas múltiplo; d) ruptura a-significante - o rizoma não pressupõe qualquer processo de significação, de hierarquização. (...) o rizoma é sempre um rascunho, um devir, uma cartografia a ser traçada sempre e novamente, a cada instante; e) cartografia - o rizoma pode ser mapeado, cartografado e tal cartografia nos mostra que ele possui entradas múltiplas; f) decalcomania - os mapas podem, no entanto, ser copiados, reproduzidos [o que não garante] uma sobreposição perfeita. [No entanto, o inverso,] colocar o mapa sobre as cópias, possibilita o surgimento de novos territórios, novas multiplicidades" (Gallo, 2000, p. 31-32).

Para Gallo (2000, p. 35), "romper com a disciplinarização, tarefa possível pela adoção de outro paradigma de saber, como o rizomático (...) significa também redesenhar o mapa estratégico do poder no campo da(s) ciência(s) e no campo da educação".

Entendemos que a socialização do poder também se faz necessária na área da saúde, para avançarmos nos trabalhos compartilhados.

Do nosso ponto de vista, se a perspectiva interdisciplinar colabora para aquisição de compreensões mais abrangentes dos conhecimentos, por sua vez a perspectiva rizomática avança, abrigando pluralidades de interpretações, criando possibilidades de circulação de saberes não disciplinares e outras competências, demandadas pela caótica e híbrida realidade contemporânea (Gallo, 2000), situação também posta para o campo da saúde.

Caminhar por essas perspectivas na formação dos profissionais da área da saúde pode ajudar na ruptura da linearidade, das verdades absolutas, na fecundação recíproca de diferentes campos do conhecimento, trazendo para 
o palco cenas de outros fazeres, de outros entendimentos, outras possibilidades, outras relações e articulações, outras dimensionalidades, movimentando nossos olhares, nossas práticas.

Não assumiremos, neste texto, uma postura favorável a uma ou outra perspectiva, uma vez que ainda vivenciamos uma tradição de trabalho pautada principalmente no modelo disciplinar e, em nosso entendimento, a interdisciplinaridade pode ser uma primeira etapa presente no processo de formação e na organização das práticas de saúde. Isto não significa que não possamos avançar buscando a perspectiva rizomática, pois, como explicitamos, as mesmas apresentam nuances diferenciadoras e potencializadoras de outras maneiras de pensar e fazer saúde.

A discussão deste tema mostra que ambas as perspectivas trazem uma atitude crítica, indo ao encontro de outros saberes, ampliando e aprofundando o saber inicial, sabendo-o sempre inconcluso, mutante - e isto requer humildade -, reconhecendo os não-saberes, ousando defrontar e reler a realidade, superar os preconceitos, descobrir e trabalhar com a diferença, com a diversidade e a pluralidade.

\section{Interdisciplinaridade, rizoma e processos de formação: desafios}

Para discutirmos as perspectivas interdisciplinar e rizomática nos processos de formação dos profissionais de saúde, é relevante considerar as diferentes e complexas realidades sociais, políticas, econômicas e culturais das populações às quais os cuidados de saúde serão destinados, uma vez que elas podem se apropriar de diferentes maneiras de conceber, compreender e pleitear saúde. Essas perspectivas procuram explicitar os múltiplos condicionantes, conexões e interpretações do processo saúde-doença em uma sociedade, em determinado período histórico.

Neste caminho é importante repensar os saberes hegemônicos e homogeneizados, socializados na tradição de um campo de saber em tempos e espaços históricos, movimentando as certezas presentes e que, sem uma contínua reflexão, acabam se reproduzindo. Amarras e convicções vêemse questionadas, denunciando a provisoriedade das ciências, dos conhecimentos acumulados e dos que estão sendo produzidos, bem como as tentativas de homogeneização de sentidos e significados destes conhecimentos nas sociedades.

Assim, as perspectivas interdisciplinar e rizomática podem provocar mudanças nos paradigmas de formação destes profissionais, considerandoos como sujeitos cuja existência concreta vai sendo tocada por diferentes vivências e experiências. Estes exercerão uma prática não neutra, compreendendo que, nas interações que se estabelecem entre os sujeitos e outros 
campos de conhecimentos, aflora a possibilidade de modificarem suas visões, concepções, maneiras de pensar e fazer, pois cada vez mais os conceitos e as idéias migram de uma área para outra, dando mobilidade aos conhecimentos.

A tentativa de vivenciar perspectivas teórico-metodológicas polissêmicas como um eixo na formação profissional é árdua, e inclui, entre outros fatores, o amadurecimento profissional e pessoal dos envolvidos, pois os profissionais especialistas são convidados a olhar para além dos contornos da sua disciplina específica e a compreender o campo curricular e das práticas como uma rede de relações complexas e interativas (Frigotto, 1995).

Vivenciar interdisciplinaridade e rizoma na prática pode também evidenciar conflitos e contradições dos que se interessam e se envolvem com estas mudanças, ficando muitas vezes difícil a visualização de rupturas e avanços.

Vários elementos confluem para que os educadores tenham dificuldades e/ou resistam ao desenvolvimento de práticas pedagógicas nestas perspectivas, como a lógica de sua formação profissional; as formas de organização da estrutura dos cursos (geralmente em departamentos), do trabalho docente e dos currículos nas universidades; a distribuição dos tempos e dos espaços dos processos educativos e de produção de conhecimentos; a disputa por recursos e territórios; as relações de poder e saber, entre outros.

$\mathrm{O}$ isolamento de pessoas e conhecimentos que geralmente ocorre sob a égide disciplinar, dificulta a emergência de novos conhecimentos, bem como a possibilidade de outras leituras ou inter-relações dos conhecimentos existentes, confluindo para outros entendimentos, num processo de comunicação constante entre sujeitos, e entre sujeitos e conhecimentos, levando-se em conta as condições estruturais.

Destacaríamos ainda outra dificuldade - a falta de uma visão mais abrangente e contextualizada do trabalho que desenvolvem, estabelecendo relações das áreas da saúde, da educação, com outras, como, por exemplo, o mundo do trabalho, as mudanças culturais, políticas, econômicas e de linguagens, articulando dialeticamente o específico na área da saúde com o geral.

Estes são desafios existentes em vários cenários, e neles os seres humanos, de maneira dinâmica, crítica, imprevisível e criativa, podem produzir olhares transversais para as ciências, para a sociedade, para os homens, compreendendo-os em sua complexidade. 


\section{Redesenhando possibilidades}

Tendo em vista as idéias e discussões apresentadas, destacamos algumas possibilidades no sentido de se incluir as perspectivas interdisciplinar e rizomática no processo de formação dos profissionais de saúde:

- repensar a organização dos cursos, que geralmente se estruturam na forma de departamentos. Nesta estrutura, a docência, a extensão e a pesquisa ainda assumem contornos pouco articulados, e o diálogo entre as diferentes disciplinas que compõem a formação tem sérias dificuldades de se concretizar, de criar canais de comunicação;

- rever os modelos curriculares que ainda se pautam na perspectiva disciplinar, pois eles pouco têm colaborado para desenvolver práticas interdisciplinares e rizomáticas. Neste sentido, alguns cursos de graduação em saúde assumiram uma organização acadêmica mais abrangente e estruturaram seus currículos em áreas temáticas, módulos ou projetos que podem propiciar o trabalho interdisciplinar e rizomático;

- estimular a vivência de outras relações e compreensões dos sujeitos com o conhecimento, das interações entre os sujeitos - professor-professor, professor-aluno, aluno-aluno -, da pesquisa com o ensino nos diferentes campos do conhecimento, da comunidade acadêmica com a sociedade, ousando se movimentar por novos territórios, novas multiplicidades;

- assumir o desenvolvimento de propostas de formação, pesquisas e grupos de estudos que incluam a interdisciplinaridade e o conhecimento rizomático, contagiando e informando nossos olhares e compreensões para além das nossas especificidades, ampliando nossa concepção de ciência, de mundo, de ser humano;

- buscar mudanças no processo de trabalho pedagógico, fazendo uma travessia de um modelo predominantemente individual para um processo que contemple também o coletivo;

- resgatar a multidimensionalidade e a multirreferencialidade dos conhecimentos presentes no processo de formação, apoiando-se em leituras críticas do contexto das políticas sociais, culturais e das concepções de saúde, de homem e de mundo, superando visões lineares e socializando saberes e poderes;

- $\quad$ situar e compreender as práticas educativas e de saúde, considerando a interdisciplinaridade e o rizoma como princípios educativos na formação contínua de docentes e futuros profissionais da área da saúde.

Mesmo apresentando as idéias acima, não há, de nossa parte, a pretensão de oferecer receitas ou caminhos para a formação dos profissionais da área da saúde. Gostaríamos, sim, que nossas vozes se somassem a outras, que aceitam o desafio de repensar este processo a partir de outros territórios, linguagens, que agenciem nossas utopias em um devir. 
Os desafios postos por estas perspectivas convidam todos os educadores envolvidos eticamente neste processo a refletirem sobre a inclusão de temas-conexões que perpassam transversalmente o processo de formação e de produção de conhecimentos, movimentando territórios, compreensões e subjetividades que dão origem a interpretações inovadoras e polissêmicas, bastante desejáveis para lidar com a complexidade da realidade e com a reorganização dos processos de formação e práticas de saúde. São multiplicidades que vão compondo paradigmas fecundos para a criação de outros sentidos para a vida, para as sociedades, para o mundo, para os conhecimentos.

\section{Notas}

${ }^{1}$ Professora da Faculdade de Educação da Universidade Estadual de Campinas (Unicamp). Coordenadora do Laboratório de Estudos e Pesquisas em Práticas de Educação e Saúde (Praesa) da Unicamp. Doutora em Educação pela Unicamp. <mbagnato@unicamp.br>

2 Professora da Faculdade de Ciências Médicas da Universidade Estadual de Campinas (Unicamp). Membro do Laboratório de Estudos e Pesquisas em Práticas de Educação e Saúde (Praesa) da Unicamp. Coordenadora do Grupo de Estudos e Pesquisas em Saúde e Trabalho da Unicamp. Doutora em Enfermagem pela Universidade de São Paulo (USP). <inesmon@obelix.unicamp.br>

\section{Referências}

BAGNATO, Maria Helena S.; RODRIGUES, Rosa Maria. 2004. A docência universitária na enfermagem brasileira: limites e possibilidades de alternativas inovadoras. In: CONGRESO INTERNACIONAL DOCENCIA UNIVERSITARIA Y INOVACIÓN, 3., Barcelona. Anais..., v. 2. Barcelona: Signo Impresió, p. 211.

BATISTA, Nildo A. 2005. Desenvolvimento docente na área da saúde: uma análise. Trabalho, Educação e Saúde, v. 3, n. 2, p. 283-294.

CASTANHO, Maria Eugênia. 2002. Professores de ensino superior da área da saúde e sua prática pedagógica. Interface, v. 6, n. 10, p. 51-62.

CHIRELLI, Mara Q.; MISHIMA, Silvana M. 2003. A formação do enfermeiro críti- co-reflexivo no curso de enfermagem da Faculdade de Medicina de Marília (Famema). Revista Latino-Americana de Enfermagem, v. 11, n. 5, p. 574-584.

DELEUZE, Gilles. 1988. Diferença e repetição. Rio de Janeiro: Graal.

. 1996. Conversações. Tradução de: Peter Pál Pelbart. Rio de Janeiro: Ed. 34. DELEUZE, Gilles; GUATARRI, Félix. 1995. Mil platôs: capitalismo e esquizofrenia, v. 1. Tradução de: Aurélio Guerra Neto e Célia Pinto Costa. Rio de Janeiro: Ed. 34.

1997. Mil platôs: capitalismo e esquizofrenia. v. 5. São Paulo: Ed. 34.

GUATTARI, Félix. 1988. O inconsciente 
maquínico: ensaios de esquizo-análise. Campinas: Papirus.

. ROLNIK, Suely. 1986. Micropolitica: cartografias do desejo. Petrópolis: Vozes. FAGUNDES, Norma C.; BURNHAM, Teresinha F. 2005. Discutindo a relação entre espaço e aprendizagem na formação de profissionais de saúde. Interface, v. 9, n. 16, p. 105-114.

FREITAS, Luís Carlos. 1989. A questão da interdisciplinaridade: notas para a reformulação dos cursos de pedagogia. Educação \& Sociedade, v. 10, n. 33, p. 105-131.

FRIGOTTO, Gaudêncio. 1995. A interdisciplinaridade como necessidade e como problema nas ciências sociais. In: JANTSCH, Ari Paulo; BIANCHETTI, Lucida (orgs.). Interdisciplinaridade: para além da filosofia do sujeito. Petrópolis: Vozes, p. 25-49.

GALLO, Sílvio. 2000. Transversalidade e educação: pensando uma educação não disciplinar. In: ALVES, Nilda; GARCIA, Regina L. (orgs.). O sentido da escola. $2^{a}$ ed. Rio de Janeiro: DP\&A, p. 17-41.

LOPES, Alice C. 2000. Organização do conhecimento escolar: analisando a disciplinaridade e a integração. In: ALVES-MAZZOTTI, Alda Judith et al. Lin- guagens, espaços e tempos no ensinar e aprender. Rio de Janeiro: DP\&A, p. 147-163.

MORIN, Edgar. 1999. Complexidade e transdisciplinaridade: a reforma da universidade e do ensino fundamental. Natal: EDUFRN.

2000. Saberes globais e saberes locais: o olhar transdisciplinar. Rio de Janeiro: Garamond.

PIRES, Marília F. de C. 1998. Multidisciplinaridade, interdisciplinaridade e transdisciplinaridade no ensino. Interface, n. 2, p. 173-181.

POMBO, Olga. 2005. Interdisciplinaridade e integração de saberes. Liinc em Revista, v. 1, n. 1, p. 4-16.

RUIZ-MORENO, Lídia et al. 2005. Jornal Vivo: relato de uma experiência de ensinoaprendizagem na área da saúde. Interface, v. 9, n. 16, p.195-204.

SANTOS FILHO, Camilo. 1992. A interdisciplinaridade na universidade: relevância e implicações. Educação Brasileira, v. 14, n. 29, p. 59-80.

SANTOS, Edméa O. dos. 2004. Idéias sobre currículo, caminhos e descaminhos de um labirinto. Revista da FAEEBA, v. 13, n. 22, p. 417- 430 .

Recebido em 28/03/2006

Aprovado em 29/05/2006 